\title{
Dairesel Bir Boruda Kullanılan Boyuna Dalgalı Kanatçıkların Isı Transferine Etkisinin Sayısal Olarak İncelenmesi
}

\author{
Erdem Işı**, Volkan Tuğan \\ Munzur Üniversitesi, Mühendislik Fakültesi, Makine Mühendisliği Bölümü, Tunceli, Türkiye \\ *erdem@munzur.edu.tr(i),volkantugan@munzur.edu.tr \\ Makale gönderme tarihi: 31.03.2021, Makale kabul tarihi: 20.04.2021
}

\begin{abstract}
$\ddot{O} \mathbf{z}$
Boruların dış yüzeyine yerleştirilen kanatçıklar ısı transferini önemli ölçüde etkilemektedir. Bu çalışmada, boyuna dalgalı kanatçıkların ısı transferine etkisini araştırmak amacıyla içerisinden 1sı transfer akışkanı olarak suyun aktığı dairesel bir borunun üç boyutlu akış analizi gerçekleştirilmiştir. Dairesel boruda $1 \mathrm{~mm}$ kalınlığa sahip 18 adet boyuna düz ve boyuna dalgalı bakır kanatçıklar kullanılmıştır. Kanatçık tipine göre kütlesel debiyle 1sı transferinin değişimini incelemek için $0,1 \mathrm{~kg} \mathrm{~s}^{-1}, 0,14 \mathrm{~kg} \mathrm{~s}^{-1}, 0,18 \mathrm{~kg} \mathrm{~s}^{-1}$ ve $0,22 \mathrm{~kg} \mathrm{~s}^{-1}$ olmak üzere dört farklı kütlesel debi kullanılmıştır. Elde edilen sonuçlara göre, boyuna dalgalı kanatçıkların boyuna düz kanatçıklara kıyasla ısı transferini en düşük \%8, en yüksek \%11 oranında arttırdığı gözlemlenmiştir.
\end{abstract}

Anahtar Kelimeler: Akış analizi, boyuna dalgalı kanatçık, 1sı transferi

\section{A Numerical Investigation into the Effect of Longitudinal Wavy Fins Used in a Circular Pipe on Heat Transfer}

\begin{abstract}
The fins placed on the outer surface of the pipes significantly affect heat transfer. In this study, in order to investigate the effect of longitudinal wavy fins on heat transfer, a three dimensional flow analysis of a circular pipe through which water flows as a heat transfer fluid was performed. In the circular pipe, 18 pieces of longitudinal straight and longitudinal wavy copper fins with a thickness of $1 \mathrm{~mm}$ were used. Four different mass flow rates, $0.1 \mathrm{~kg} \mathrm{~s}^{-1}, 0.14 \mathrm{~kg} \mathrm{~s}^{-1}, 0.18 \mathrm{~kg} \mathrm{~s}^{-1}$ and $0.22 \mathrm{~kg} \mathrm{~s}^{-1}$, were used to examine the change of heat transfer with mass flow rate according to the fin type. According to the results, it was observed that longitudinal wavy fins increased heat transfer by a minimum of $8 \%$ and a maximum of $11 \%$ compared to longitudinal straight fins.
\end{abstract}

Keywords: Flow analysis, longitudinal wavy fin, heat transfer

\section{GİRIS}

Günümüzde, mühendislik uygulamalarında en sık karşılaşılan işlemlerden birisi farklı sıcaklıklara sahip iki veya daha fazla akıșkan arasında meydana gelen 1s1 transferidir. Is1 transferinin gerçekleştiği cihazlar 1s1 değiştirici olarak adlandırılır. Isı değiştiriciler kullanım amaçlarına göre değişik tiplerde, kapasitelerde ve boyutlarda üretilmektedirler (Bayram ve Şahin, 2014). Kompakt 1S1 değiştiriciler, endüstriyel sistemlerde en s1k kullanılan 1sı değiştiricilerden birisidir ve diğer 1S1 değiştiricilere kıyasla geniş 1s1 transfer alanına sahiptirler (Işık ve Tuğan, 2021). Küçük bir hacime sahip olmalarına rağmen yüksek 1sı transfer hızı sağlarlar (Incorpera ve ark., 2010). Bu 1s1 değiștiricilerde 1S1 transfer hızında elde edilebilecek küçük miktarlardaki artış, enerji tasarrufu açısından büyük geri dönüşler sağlayacaktır. Kompakt 1s1 değiştiriciler çoğunlukla 1Sı taşınım katsayısının düşük ve en az bir akışkanın gaz olduğu uygulamalarda kullanılırlar. Kompakt bir 1s1 değiştirici tipi olan kanatı borulu 1sı değiştiricilerinde kanatlar arasında akan havanın ve boru içerisinde dolaşan akışkanın 1sı taşınım katsayısı değeri büyük önem taşımaktadır. Genellikle hava tarafındaki is1 taşınım katsayısı, boru içindeki 1s1 taşınım katsayısından daha düşüktür. Isı transferi, sıcak olan bölgeden daha düşük sıcaklığa sahip bölgeye doğru gerçekleşir (Incorpera ve ark., 2010; Işık ve Tuğan, 
2017). Is1 değiştiricilerinde 1sı transferini artırmak için genelde yüzey alanını artıran elemanlar kullanılmaktadır (Karakaya ve Durmuş, 2013). Bu elemanlar akış düzensizliğinden dolayı basınç değişimleri meydana getirirler (Özdemir ve Kahraman, 2020). Boruların dış yüzeyine yerleştirilen kanatçıklar ile 1sı transfer alanını artırmak amaçlanmaktadır (Çelik ve Parlak, 2018). Kanatçıklar genellikle bakır ve alüminyum gibi isıl iletkenlik katsayısı yüksek malzemelerden üretilirler (Cüce, 2020). Kanatçıklı yüzeyler, elektronik cihazların ve türbin kanatçıklarının soğutulması, havacilık ve uzay sanayii, kimyasal üretim tesislerinde kullanılan 1S1 değiştiriciler gibi birçok uygulama alanında yaygın bir şekilde kullanılmaktadır (Buyruk ve Karabulut, 2017). Kanatçıkların geometrik yapısı 1sı transferini önemli ölçüde etkilemektedir.

Literatürde 1sıl performansin arttrrılması amaciyla farklı geometrik yapıya ve düzene sahip kanatçıklar üzerine birçok çalışma yapılmıştır. Maakoul ve ark. (2020) boyuna kanatçıklara sahip çift borulu bir 1s1 değiştiricinin termohidrolik performansını araştırmışlardır. Çalışmada, kanatçık tipinin isıl performansa etkisini incelemek amaciyla bölünmüş boyuna kanatçıklar ve geleneksel boyuna kanatçıklar kullanılmıştır. Elde edilen sonuçlara göre, bölünmüş boyuna kanatçıkların kullanıldığı durumda elde edilen is1 transfer oranının geleneksel boyuna kanatçıklara kıyasla \%31-48 daha yüksek olduğu görülmüştür. Hosseini ve ark. (2015) faz değiştiren malzeme içeren çift borulu 1s1 değiştiricilerinde boyuna kanatçıkların etkisini deneysel ve sayısal olarak incelemişlerdir. Çalışmada, kanatçık yüksekliğinin 1sı değiştiricinin termal performansı üzerindeki etkisini araştırmak amacıyla iki farklı kanatçık yüksekliği kıyaslanmıştır. Sonuçlar, kanat uzunluğunun daha kısa erime süresine yol açtığını göstermiştir. Kazemi ve ark. (2018), faz değişimi sırasında boyuna kanatçık açısının 1sı transferi üzerindeki etkilerini araştırmışlardır. Çalışmada, faz değişim malzemesi olarak RT 35 kullanmışlardır. RT 35'in erime işlemi iki ve üç kanatlı durumlar için farklı açılarda incelenmiştir. Elde edilen sonuçlara göre, üç kanatlı 1sı değiştiricilerinde kanat açısının $60^{\circ}$ 'den $120^{\circ}$ 'ye çıkmasıyla toplam erime süresinin azaldığ görülmüştür. Çift kanatlı 1sı değiştiricilerinde ise açının $150^{\circ}$ den $45^{\circ}$ ye düşürülmesi ile erime süresinin azaldığı ve açının daha fazla küçülmesinin erime süresini arttırdığı görülmüş̧ür. Abdulateef ve ark. (2017) üç borulu bir 1s1 değiştiricide boyuna kanatçıkların etkisini deneysel ve sayısal olarak araştırmışlardır. Çalışmada, $16,2 \mathrm{~kg} \mathrm{~s}^{-1}, 29,4 \mathrm{~kg} \mathrm{~s}^{-1}$ ve $37,4 \mathrm{~kg} \mathrm{~s}^{-1}$ olmak üzere üç farklı kütlesel debi ve boyuna ve üçgensel olmak üzere iki farklı kanatçık tipi incelenmiştir. Elde edilen sonuçlara göre, faz değişim malzemesinin erime süresi açısından iç, içdış ve dış üçgensel kanatçıkların boyuna kanatçıklara kıyasla sırasıyla $\% 11, \% 12$ ve $\% 15$ iyileşme sağladığ gözlemlenmiştir.

Zhang ve ark. (2020) gizli 1s1 depolama sistemlerinde kanatçık yapısının faz değiştiren malzemenin erime süresine etkisini sayısal olarak araştırmışlardır. Çalışmadan elde edilen sonuçlara göre, kanatçık yapısının faz değiştiren malzemenin erime süresi üzerinde önemli etkiye sahip olduğu anlaşılmıştır. Dikey bir gizli ısı depolama sisteminde, en iyi termal performansın çift helisel kanatçık için, yatay bir gizli 1sı depolama sisteminde ise dört katlı helisel kanatçık için elde edildiği gözlemlenmiştir. Cüce (2020) geleneksel ve oyuklu boyuna kanatçıkların 1Sı transferine etkisini sayısal olarak araştırmıştır. Çalışmadan elde edilen sonuçlara göre, boyuna oyuklu kanatçıklarda geleneksel kanatçığa göre 1sı transferinin daha az fakat birim kanat hacmi başına düşen 1Sı transferine göre oyuklu kanatçıkların daha etkin olduğu gözlemlenmiştir. Ek olarak, oyukların kanatçıkların ağırlığını önemli ölçüde azalttığını ve düşük taşınım katsayısı değerlerinde oyuk etkilerinin daha belirgin olduğu görülmüştür. Koca ve Budak (2021) dikey konumlandırılmış bir iç içe borulu 1sı değiştiricisinde içteki borunun kanatçıklı olmasının 1sı transferi ve basınç düşüşüne etkisini deneysel olarak incelemişlerdir. Elde edilen bulgulara göre, en yüksek 1S1 transferinin kanatçık sayıs1 en çok olan iç boruda meydana geldiği tespit edilmiştir. Kanatçıklı bölgenin uzunluğunun $300 \mathrm{~mm}$ olduğu boruda meydana gelen 1s1 transferinin ve basınç düşüşünün düz boruya göre sırasılyla $\% 147,38$ daha fazla ve $\% 131,25$ daha az olduğu gözlemlenmiştir. Kumar ve Verma (2020) yatay bir gövde borulu enerji depolama sisteminde boyuna kanatçıkların konumunun faz değişim malzemesinin erime özelliklerine etkisini deneysel ve sayısal olarak araştırmışlardır. Çalışmada, farklı kanatçıklara sahip içteki borunun üç farklı eksantirik konumu ve kanatçıklar arasındaki üç farklı açının ısı transferine etkileri incelenmiştir. Elde edilen sonuçlara göre, kanatçıklar arasındaki açının $60^{\circ}$ olduğu durumun $120^{\circ}$ ve $180^{\circ}$ olanlara kıyasla faz değişim 
malzemesinin erime performansını sırasıly $\% 6$ ve \%7 arttırdığı gözlemlenmiștir. Ek olarak, maksimum eksantrik düzende $(E=0,70)$ eriyen faz değişim malzemesinin eş merkezli düzene göre \%21 daha fazla olduğu bulunmuştur.

$\mathrm{Bu}$ çalışmada, dairesel bir boruda yeni bir kanatçık tipi olan boyuna dalgalı kanatçıklar kullanılmış ve dört farklı kütlesel debiye $\left(0,1 \mathrm{~kg} \mathrm{~s}^{-1}\right.$, $0,14 \mathrm{~kg} \mathrm{~s}^{-1}, 0,18 \mathrm{~kg} \mathrm{~s}^{-1}$ ve $0,22 \mathrm{~kg} \mathrm{~s}^{-1}$ ) göre kanatçıkların 1sı transferine etkisi sayısal olarak incelenmiştir. Ayrıca, boyuna dalgalı kanatçıkları 1sı transferi açısından boyuna düz kanatçıklar ile kıyaslamak amaçlanmıştır. Elde edilen sonuçlar, konturlar ve grafikler şeklinde sunulmuştur.

\section{MATERYAL VE METOT}

Bu çalışmada, dairesel bir boruda kanatçık tipinin 1S1 transferine etkisini incelemek amaciyla boyuna dalgalı kanatçıklara ve boyuna düz kanatçıklara sahip iki farklı model tasarlanmıştır. Üç boyutlu ak1ş analizini gerçekleştirmek için bir Hesaplamalı Akışkanlar Dinamiği (HAD) yazılımı olan ANSYS Fluent programı kullanılmıştır.

\section{Fiziksel Model}

Analizlerde kullanılan dairesel bakır boru 24 $\mathrm{mm}$ dış çapa, $20 \mathrm{~mm}$ iç çapa ve $850 \mathrm{~mm}$ uzunluğa sahiptir. Şekil 1'de görüldüğü üzere boyuna dalgalı kanatçık ve boyuna düz kanatçık olmak üzere iki farklı kanatçık tipi kıyaslanmıştır. Her iki kanatçık için de dairesel borunun diş yüzeyinde toplam 18 adet bakır kanatçık kullanılmıştır. Kanatçıkların yüksekliği $10 \mathrm{~mm}$, kalınlığı $1 \mathrm{~mm}$ ve uzunluğu 800 mm olarak belirlenmiştir.

Analizlerde 1sı transfer akışkanı olarak su kullanılmıştır. Suya ait termofiziksel özellikler Tablo 1 'de verilmiştir.

\section{Yürütülen Eşitlikler}

Boyuna dalgalı ve düz kanatçıklara sahip dairesel borunun üç boyutlu akış analizinin çözümlenmesinde standart k- $\varepsilon$ türbülans modeli kullanılmıştır. Isı transferi ve akış probleminin çözümlemesi, sürekli rejimde kütlenin, momentumun ve enerjinin korunumu denklemlerinin çözülmesi esasına dayanır. Bu denklemler aşağıda verilmiştir: Süreklilik denklemi:

$$
\frac{\partial u}{\partial x}+\frac{\partial v}{\partial y}+\frac{\partial w}{\partial z}=0
$$

x momentum denklemi:

$\rho\left(u \frac{\partial u}{\partial x}+v \frac{\partial v}{\partial y}+w \frac{\partial w}{\partial z}\right)=-\frac{\partial P}{\partial x}+\mu\left(\frac{\partial^{2} u}{\partial x^{2}}+\frac{\partial^{2} u}{\partial y^{2}}+\frac{\partial^{2} u}{\partial z^{2}}\right)$

y momentum denklemi:

$\rho\left(u \frac{\partial v}{\partial x}+v \frac{\partial v}{\partial y}+w \frac{\partial v}{\partial z}\right)=-\frac{\partial P}{\partial y}+\mu\left(\frac{\partial^{2} v}{\partial x^{2}}+\frac{\partial^{2} v}{\partial y^{2}}+\frac{\partial^{2} v}{\partial z^{2}}\right)$

z momentum denklemi:

$$
\begin{aligned}
\rho\left(u \frac{\partial w}{\partial x}+v \frac{\partial w}{\partial y}+\right. & \left.w \frac{\partial w}{\partial z}\right) \\
& =-\frac{\partial P}{\partial z}+\mu\left(\frac{\partial^{2} w}{\partial x^{2}}+\frac{\partial^{2} w}{\partial y^{2}}+\frac{\partial^{2} w}{\partial z^{2}}\right)
\end{aligned}
$$

Enerji denklemi:

$$
u \frac{\partial T}{\partial x}+v \frac{\partial T}{\partial y}+w \frac{\partial T}{\partial z}=\left(\frac{k}{\rho c_{p}}\right)\left(\frac{\partial^{2} T}{\partial x^{2}}+\frac{\partial^{2} T}{\partial y^{2}}+\frac{\partial^{2} T}{\partial z^{2}}\right)
$$

Yukarıdaki denklemlerde u, v ve w sirasıyla x, y ve $\mathrm{z}$ yönlerindeki hızları temsil etmektedir. $\mathrm{k}^{\prime}$, türbülans kinetik enerjisini, $\varepsilon$, dissipasyon terimini, $\Phi$ viskoz kaybolma terimini temsil etmektedir.

Türbülans kinetik enerjisi denklemi:

$$
\begin{aligned}
\frac{\partial\left(\rho u k^{\prime}\right)}{\partial x}+\frac{\partial\left(\rho v k^{\prime}\right)}{\partial y} & +\frac{\partial\left(\rho w k^{\prime}\right)}{\partial z} \\
& =\frac{\partial}{\partial x}\left(\frac{\mu_{t}}{\sigma_{k}} \frac{\partial k^{\prime}}{\partial x}\right)+\frac{\partial}{\partial y}\left(\frac{\mu_{t}}{\sigma_{k}} \frac{\partial k^{\prime}}{\partial y}\right) \\
& +\frac{\partial}{\partial z}\left(\frac{\mu_{t}}{\sigma_{k}} \frac{\partial k^{\prime}}{\partial z}\right)+\mu_{t} \Phi-\rho \varepsilon
\end{aligned}
$$

Türbülans viskozitesi $\left(\mu_{t}\right)$ :

$\mu_{t}=C_{\mu} \rho \frac{k^{\prime 2}}{\varepsilon}$

Türbülans kinetik enerji $\left(k^{\prime}\right)$ :

$k^{\prime}=\frac{1}{2}\left(\overline{u^{\prime 2}}+\overline{v^{\prime 2}}+\overline{{w^{\prime}}^{2}}\right)$

Viskoz kaybolma terimi $(\Phi)$ :

$\Phi=2 \mu\left[\left(\frac{\partial u}{\partial x}\right)^{2}+\left(\frac{\partial v}{\partial y}\right)^{2}\right]+\mu\left(\frac{\partial v}{\partial x}+\frac{\partial u}{\partial y}\right)^{2}$ 
Türbülans kinetik enerji kaybolma denklemi:

$$
\begin{aligned}
\frac{\partial(\rho u \varepsilon)}{\partial x}+\frac{\partial(\rho v \varepsilon)}{\partial y}+ & \frac{\partial(\rho w \varepsilon)}{\partial z} \\
& =\frac{\partial}{\partial x}\left(\frac{\mu_{t}}{\sigma_{e}} \frac{\partial \varepsilon}{\partial x}\right)+\frac{\partial}{\partial y}\left(\frac{\mu_{t}}{\sigma_{e}} \frac{\partial \varepsilon}{\partial y}\right)+\frac{\partial}{\partial z}\left(\frac{\mu_{t}}{\sigma_{e}} \frac{\partial \varepsilon}{\partial z}\right) \\
& +C_{1 \varepsilon} \mu_{t} \frac{\varepsilon}{k^{\prime}} \Phi-C_{2 \varepsilon} \rho \frac{\varepsilon^{2}}{k^{\prime}}
\end{aligned}
$$

Yukarıdaki denklemlerde $C_{\mu}, C_{1 \varepsilon}, C_{2 \varepsilon}, \sigma_{k}, \sigma_{e}$ katsayıların sabit olup $C_{\mu}=0,09, \quad C_{1 \varepsilon}=1,44$, $C_{2 \varepsilon}=1,92, \quad \sigma_{k}=1, \quad \sigma_{e}=1,3$ 'tür (Buyruk ve Karabulut, 2017; Wang ve ark., 2009).

\section{Sınır Şartları}

Boyuna kanatçıklara sahip dairesel boru için yürütülen analizler üç boyutlu, sürekli rejimde ve basınca dayalı olarak gerçekleştirilmiştir. Tüm yüzeylere kaymama sınır şartı ve yüzeye yakın kısımlara standart duvar fonksiyonları yöntemi

\section{a-)}

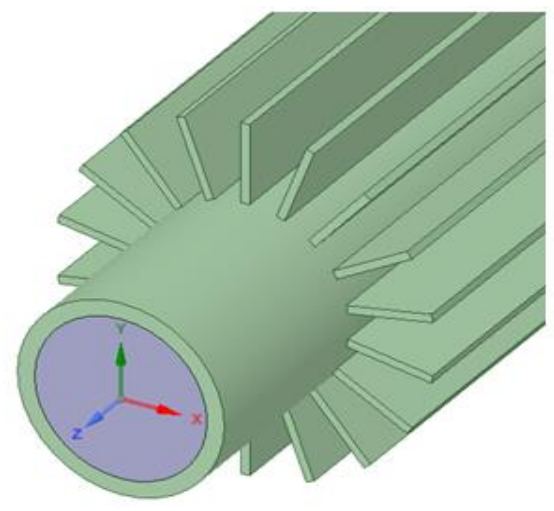

uygulanmıştır. Analizlerde yerçekiminin etkisi ihmal edilmiştir. Çalışma akışkanının boruya $345 \mathrm{~K}$ sicaklikta ve $0,1 \mathrm{~kg} \mathrm{~s}^{-1}, 0,14 \mathrm{~kg} \mathrm{~s}^{-1}, 0,18 \mathrm{~kg} \mathrm{~s}^{-1}$ ve 0,22 $\mathrm{kg} \mathrm{s}^{-1}$ olmak üzere dört farklı kütlesel debide girdiği varsayılmıştır. Dairesel kanaldaki akış tam gelişmiş ve türbülanslıdır. Dairesel borudan 1sının $295 \mathrm{~K}$ sıcaklığındaki dış ortama $75 \mathrm{~W} \mathrm{~m} \mathrm{~m}^{-2} \mathrm{~K}^{-1}$ 1sı taşınım katsayısıyla aktarıldığı kabulü yapılmıştır.

\section{Ăgdan Bă̆ımsızlık}

Şekil 2'de görüldüğü üzere ağdan bağımsızlık analizi için 1741 790, 2193 988, 2806300 ve 3552 081 olmak üzere 4 farklı ağ sistemi oluşturulmuş ve 1S1 transferi açısından değerlendirilmiştir. $0,1 \mathrm{~kg} \mathrm{~s}^{-1}$ kütlesel debide 1sı transferi açısından son iki ağ sistemi arasındaki farkın \%0,1'den az olduğu görülmüştür. $\mathrm{Bu}$ sebeple, 2806300 elemanlı ağ sisteminin analizlerin doğruluğu açısından yeterli olduğu kabul edilmiştir.

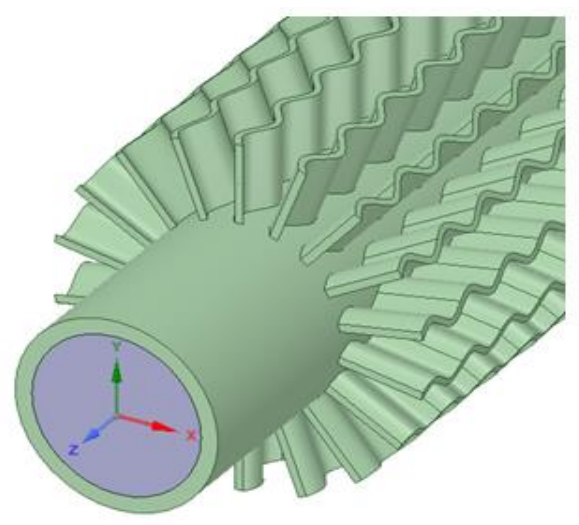

Şekil 1. a-) Boyuna düz kanatçıklı dairesel boru b-) Boyuna dalgalı kanatçıklı dairesel boru

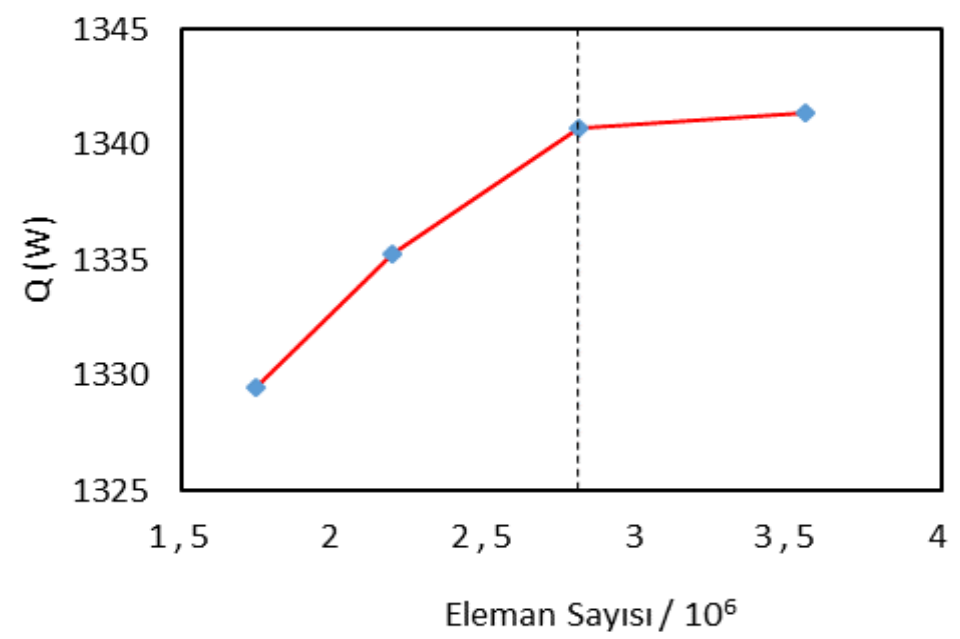

Şekil 2. A ̆gdan bağımsızlık analizi 
Tablo 1. Suyun $\left(72{ }^{\circ} \mathrm{C}\right)$ termofiziksel özellikleri

\begin{tabular}{|l|l|}
\hline Termofiziksel Özellikler & Değer \\
\hline$\rho\left(\mathrm{kg} \mathrm{m}^{-3}\right)$ & 976,1 \\
\hline$c_{\mathrm{p}}\left(\mathrm{J} \mathrm{kg}^{-10} \mathrm{C}^{-1}\right)$ & 4192 \\
\hline$\mu\left(\mathrm{kg} \mathrm{m}^{-1} \mathrm{~s}^{-1}\right)$ & 0,000391 \\
\hline $\mathrm{k}\left(\mathrm{W} \mathrm{m}^{-10} \mathrm{C}^{-1}\right)$ & 0,665 \\
\hline
\end{tabular}

\section{TARTIŞMA VE SONUÇ}

Boyuna dalgalı ve düz kanatçıkların 1S1 transferine etkisini incelemek amaciyla yapılan CFD analizlerinden elde edilen sonuçlar, konturlar ve grafikler şeklinde verilerek yorumlanmıștır. $0,22 \mathrm{~kg}$ $\mathrm{s}^{-1}$ kütlesel debide boyuna düz kanatçıklara sahip dairesel boru için elde edilen üç boyutlu sicaklık dağılımı ve bu sıcaklık dağılımının çıkış yüzeyinden görünümü sırasıyla Şekil 3 ve Şekil 4'te verilmiştir. Aynı şartlar altında boyuna dalgalı kanatçıklara sahip dairesel boru için elde edilen sıcaklık dağılımları ise Şekil 5 ve Şekil 6' da verilmiştir. Çıkış yüzeyinden elde edilen sıcaklık dağılımlarına göre, boyuna dalgalı kanatçıkların kullanılması durumunda elde edilen çıkış sıcaklığının boyuna düz kanatçıklara göre daha düşük olduğu görülmektedir.

Isı transfer akışkanının dairesel borudan çıkış sıcaklıkları kullanılarak elde edilen sonuçlara göre boyuna düz ve boyuna dalgalı kanatçıkların 1S1 transferine etkisini gösteren grafik Şekil 7'de verilmiştir. Boyuna dalgalı kanatçıkların kullanılması durumunda akışkanın sistemden çıkış sıcaklığının daha düşük olduğu ve dolayısıyla dairesel bir boruda kullanılan boyuna dalgalı kanatçıkların boyuna düz kanatçıklara göre 1s1 transferini arttırdığ gözlemlenmiştir. Ek olarak, kütlesel debinin artmasıyla 1sı transferinin de arttığ1 görülmüştür. En yüksek 1s1 tranferinin $0,22 \mathrm{~kg} \mathrm{~s}^{-1}$ debide boyuna dalgalı kanatçıkların kullanılmasıyla elde edildiği bulunmuştur

$\mathrm{Bu}$ çalışmada kullanılan modele yakın çalışmalar incelendiğinde, Maakoul ve ark. (2020) yapmış oldukları çalışmada, bölünmüş boyuna kanatçıkların geleneksel boyuna kanatçıklara kıyasla 1sı transferini en düşük $\% 31$, en yüksek $\% 48$ oranında arttırdığı sonucuna ulaşmışlardır. Bu çalışmada ise boyuna dalgalı kanatçıkların boyuna düz kanatçıklara kıyasla 1s1 transferini en düşük $\% 8$, en yüksek $\% 11$ oranında arttırdığ 1 bulunmuştur.

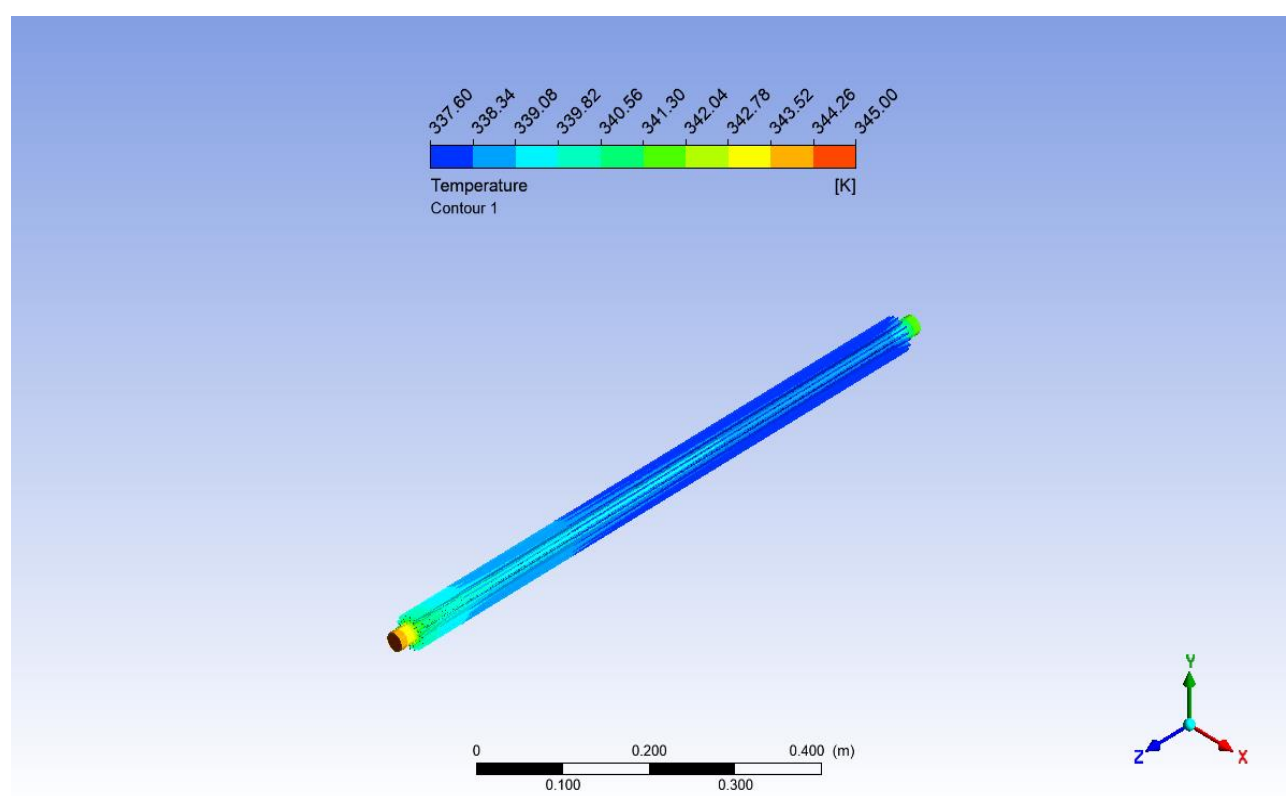

Şekil 3. Boyuna düz kanatçıklara sahip dairesel boru için üç boyutlu sıcaklık dağılımı 

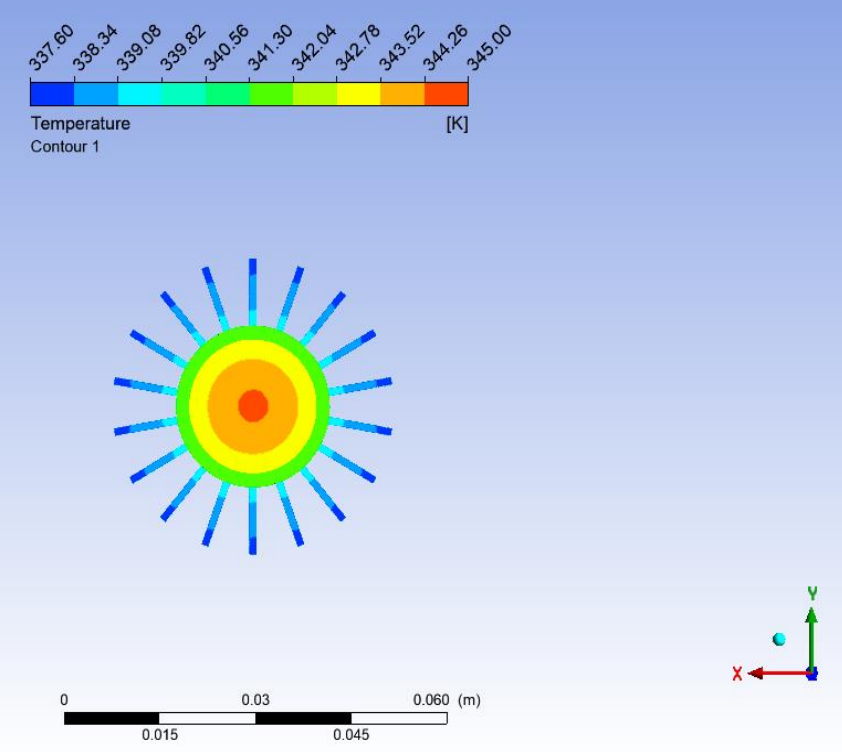

Şekil 4. Boyuna düz kanatçıklara sahip dairesel boru için sıcaklık dağılımının çıkış yüzeyinden görünümü

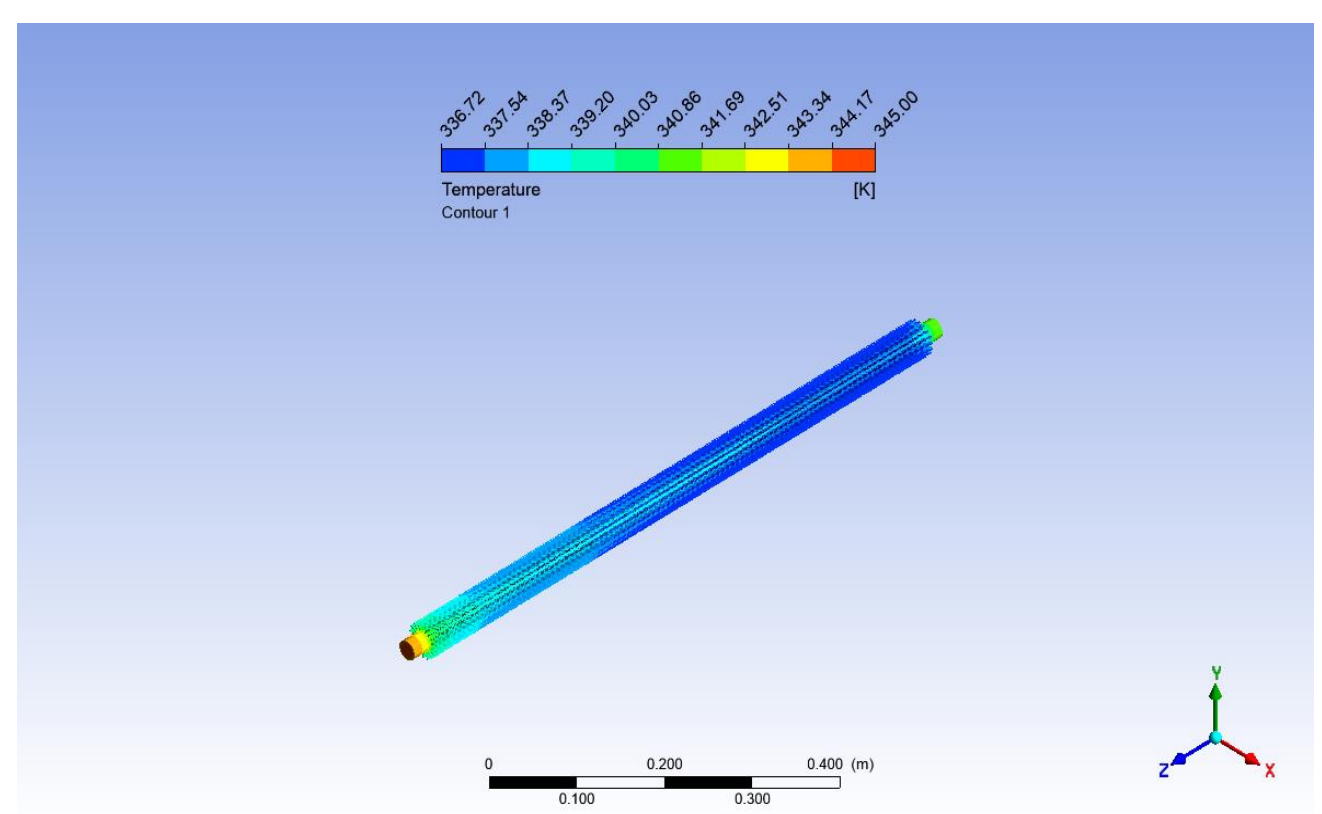

Şekil 5. Boyuna dalgahı kanatçıklara sahip dairesel boru için üç boyutlu sıcaklık dağılımı 


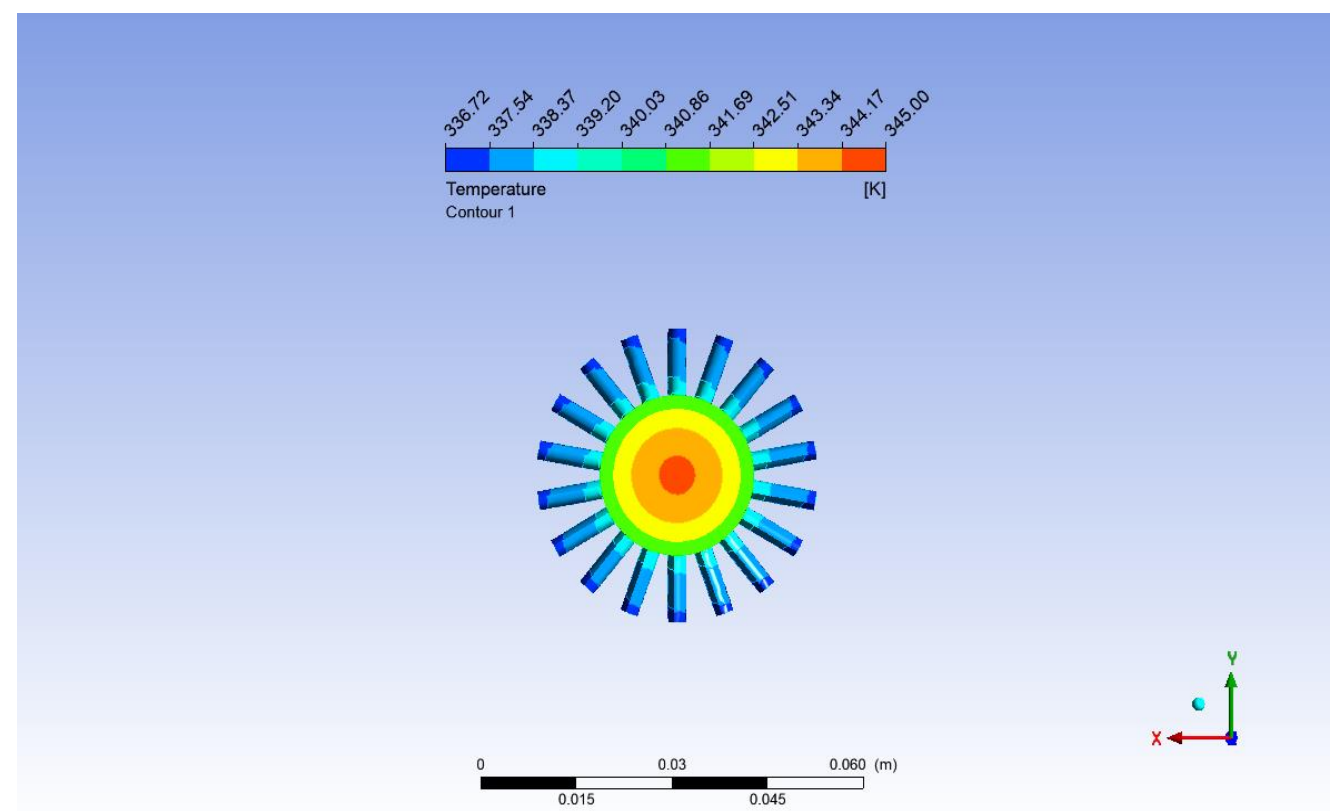

Şekil 6. Boyuna dalgalı kanatçıklara sahip dairesel boru için sıcaklık dağılımının çıkış yüzeyinden görünümü

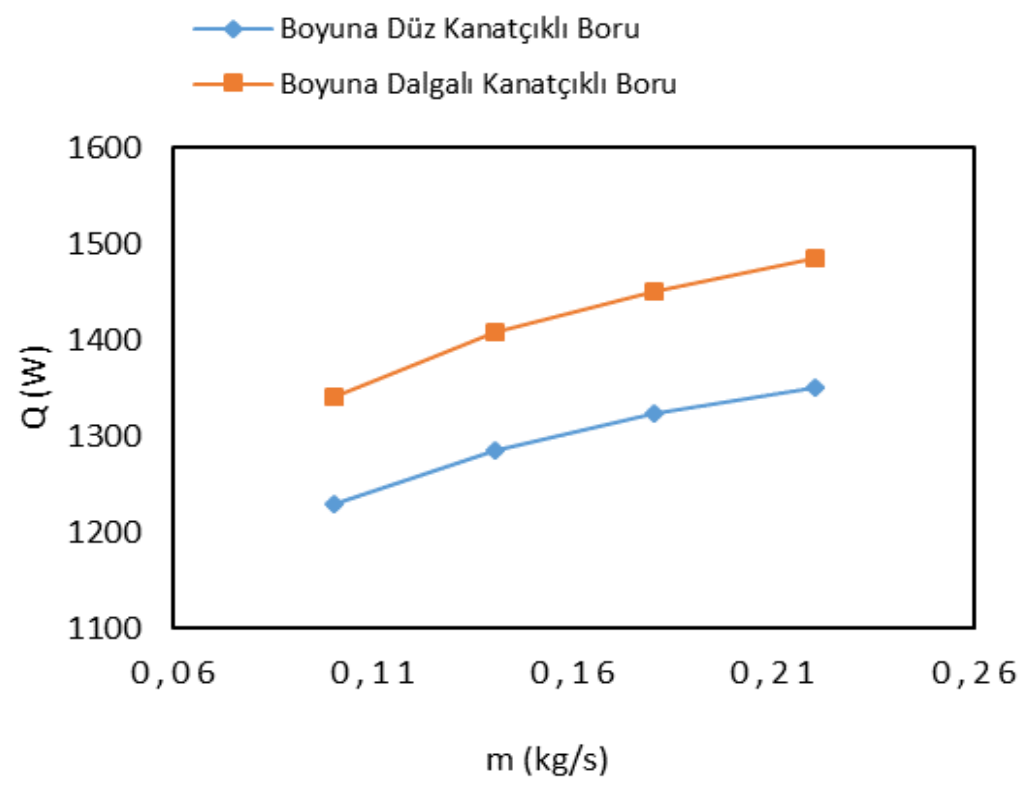

Şekil 7. Kanatçık tipine göre kütlesel debi ile 1sı transferinin değişimi

\section{SONUÇLAR}

$\mathrm{Bu}$ çalışmada, boyuna düz ve boyuna dalgalı kanatçıkların dairesel bir boruda meydana gelen isı transferine etkisi sayısal olarak incelenmiştir. Dairesel borudan akan suyun çıkış sıcaklıklarına göre elde edilen sonuçlar, konturlar ve grafikler şeklinde gösterilmiştir. Analizlerden elde edilen sonuçlara göre, boyuna dalgalı kanatçıkların boyuna düz kanatçıklara kıyasla 1S1 transferini \%8-11 oranında iyileştirdiği görülmüştür. Ek olarak, kütlesel debinin $0,1 \mathrm{~kg} \mathrm{~s}^{-1}$, den $0,22 \mathrm{~kg} \mathrm{~s}^{-1}$ ye kademeli olarak artmasıyla her iki kanatçık durumu için de 1 s1 
transferinin belirgin bir şekilde $\operatorname{arttığ}$ gözlemlenmiştir. İleride yapılacak çalışmalarda boyuna dalgalı kanatçıklarda kanatçık yüksekliğinin, sayısının ve eğim açısının 1sı transferine etkisi incelenebilir.

\section{Semboller ve Kisaltmalar}

$c_{p}$ : Sabit basınçta özgül 1sı $\left(\mathrm{J} \mathrm{kg}^{-1 \circ} \mathrm{C}^{-1}\right)$

$\dot{m}$ : Kütlesel debi $\left(\mathrm{kg} \mathrm{s}^{-1}\right)$

$Q$ : Is1 transferi (W)

$\mathrm{P}$ : $\operatorname{Basinç~}(\mathrm{Pa})$

T: Sicaklik (K)

$\rho$ : Yoğunluk $\left(\mathrm{kg} \mathrm{m}^{-3}\right)$

$\mu$ : Dinamik viskozite $\left(\mathrm{kg} \mathrm{m}^{-1} \mathrm{~s}^{-1}\right)$

$\mathrm{k}$ : Isıl iletkenlik katsayısı $\left(\mathrm{W} \mathrm{m}^{-1}{ }^{\circ} \mathrm{C}^{-1}\right)$

\section{ÇIKAR ÇATIŞMASI BEYANI}

Yazar/ Yazarlar bu makale ile ilgili herhangi bir çıkar çatışması bildirmemektedir.

\section{ARASSTIRMA VE YAYIN ETİĞİ BEYANI}

Yazar/Yazarlar bu çalışmanın araştırma ve yayın etiğine uygun olduğunu beyan eder.

\section{KAYNAKLAR}

Abdulateef, A. M., Mat, S., Sopian, K., Abdulateef, J., Gitan, A. A., 2017. Experimental and computational study of melting phase-change material in a triplex tube heat exchanger with longitudinal/triangular fins. Solar Energy, 155: 142-153.

Bayram, G., Şahin, A. Ş., 2014. Plakalı 1sı eşanjöründe farklı soğutkanlar kullanılarak iki farklı soğutma sisteminin deneysel analizi. SDÜ Yekarum e-Dergi, 2(2): 20-25.

Buyruk, E., Karabulut, K., 2017. Plakalı kanatçıklı 1sı değiştiricilerde kanat açısının 1sı transferine olan etkisinin üç boyutlu sayısal olarak incelenmesi. Çukurova Üniversitesi Mühendislik Mimarlık Fakültesi Dergisi, 32(1): 49-62.

Cüce, E., 2020. Boyuna uzatılmış yüzeylerde dikdörtgensel oyukların 1sı atımına etkisi: bir hesaplamalı akışkanlar dinamiği analizi. Afyon Kocatepe Üniversitesi Fen ve Mühendislik Bilimleri Dergisi, 20: 931-940.

Çelik, H., Parlak, N., 2018. Kanatçık geometrisinin 1sı geçişine etkisinin parametrik incelenmesi. International Journal of Multidisciplinary Studies and Innovative Technologies, 2(2): 25-29.

Hosseini, M. J., Ranjbar, A. A., Rahimi, M., Bahrampoury, R., 2015. Experimental and numerical evaluation of longitudinally finned latentheat thermal storage systems. Energy and Buildings, 99: 263-272.
Incropera, F. P., Dewitt, D. P., Derbentli, T., 2010. Is1 ve kütle geçişinin temelleri. Literatür yayınları.

Işık, E., Tuğan, V., 2021. Çiçek tip şaşırtma levhasına sahip gövde borulu 1sı değiştiricinin CFD analizi. Iğdır Üniversitesi Fen Bilimleri Enstitüsü Dergisi, 11(1): 428-439.

Işı1k, E., Tuğan, V., 2017. Tunceli, Hakkâri ve Kars İllerinin Optimum Isı Yalıtım Kalınlığının Hesaplanmasi. International Journal of Pure and Applied Sciences, 3(2): 50-57.

Karakaya, H., Durmuş, A., 2013. Heat transfer and exergy loss in conical spring turbulators. International Journal of Heat and Mass Transfer, 60: 756-762.

Kazemi, M., Hosseini, M. J., Ranjbar, A. A., Bahrampoury, R., 2018. Improvement of longitudinal fins configuration in latent heat storage systems. Renewable Energy, 116: 447-457.

Koca, T., Budak, S. A., 2021. Kanatçıklı iç borulu dikey 1s1 değiştiricilerinde 1S1 transferi ve basınç düşümü analizi. Gümüşhane Üniversitesi Fen Bilimleri Enstitüsü Dergisi, 11(1): 62-72.

Kumar, R., Verma, P., 2020. An experimental and numerical study on effect of longitudinal finned tube eccentric configuration on melting behaviour of lauric acid in a horizontal tube-in-shell storage unit. Journal of Energy Storage, 30: 101396.

Maakoul, A. E., Feddi, K., Saadeddine, S., Abdellah, A. B., Metoui, M. E., 2020. Performance enhancement of finned annulu using surface interruptions in doublepipe heat exchangers. Energy Conversion and Management, 210: 112710.

Özdemir, O., Kahraman, G., 2020. Hidrolik santrallerde kavitasyon olayının neden olduğu arızalar ve çözüm yöntemleri. International Journal of Pure and Applied Sciences, 6(2): 169-178.

Wang, Y. Q., Dong, Q. W., Liu, M. S., Wang, D., 2009. Numerical study on plate fin heat exchangers with plain fins and serrated fins at low Reynolds Number. Chem. Eng. \&Tec., 32 (8): 1219-1226.

Zhang, S., Pu, L., Xu, L., Liu, R., Li, Y., 2020. Melting performance analysis of phase change materials in different finned thermal energy storage. Applied Thermal Engineering, 176: 115425. 